\title{
Resenha
}

\author{
Bruna Fetter
}

\section{Documenta 14: o que ainda podemos aprender com a arte?}

\section{Resumo}

Sob elogios e muitas controvérsias, a documenta 14, com direção artística do polonês Adam Szymczyk, foi pautada por um forte discurso curatorial. Tendo se dividido entre sua habitual localização na cidade de Kassel, na Alemanha, e a capital da Grécia, a grande mostra partiu do mote "Learning from Athens", para apresentar uma abordagem de caráter político, que problematizou complexas discussões da contemporaneidade ao mesmo tempo em que se propôs a questionar narrativas históricas da arte.

\section{Palavras-chave}

Documenta 14. Arte contemporânea. Atenas. Narrativas históricas. Arte política. 
Ao se dividir entre as cidades de Atenas, na Grécia, de 08 de abril a 16 de julho e Kassel, na Alemanha, de 10 de junho a 17 de setembro de 2017, a 14ª edição da documenta fugiu ao usualmente esperado da grande mostra. Isso pode ser entendido sob uma variedade de perspectivas, sejam positivas ou negativas. Este texto é uma tentativa de contribuir ao seu entendimento, problematizando algumas das questões que emergiram ao visitar a mostra.

\section{DESAPRENDER PARA APRENDER}

"Learning from Athens" (Aprendendo desde/com Atenas) foi o título da documenta 14, capitaneada pelo curador polonês Adam Szymczyk. Um título que gerou controvérsias desde sua divulgação, em especial por comunicar a divisão da mostra entre a tradicional cidade alemã de Kassel e a capital grega. Tal

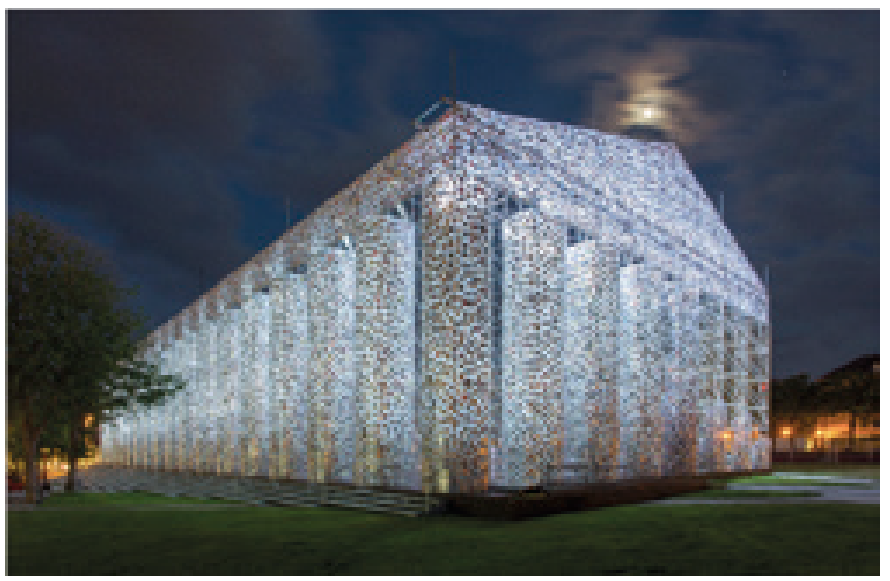
deslocamento foi pautado por críticas tanto por parte da imprensa e de instituições alemãs, quanto da comunidade artística grega, tendo gerado debates no âmbito internacional a respeito da complexa relação entre os dois países nos planos político e econômico, e se estendendo a discussões de pós-colonialismo e neocolonialismo na já desgastada relação norte-sul. Se a Grécia enfrenta atualmente um cenário de profunda recessão econômica,

Figura 1. Marta Minujín, The Parthenon of Books (2017). Aço, livros e folhas de plástico, Friedrichsplatz, Kassel. Foto: Roman März ${ }^{1}$

1. Todas as imagens selecionadas para acompanhar a publicação deste texto foram retiradas do site oficial da documenta 14 e estão legendadas conforme consta no site: http://www.documenta14.de/en/. com fortes medidas de austeridade tendo sido exigidas como condição para sua continuidade na União Europeia, a Alemanha representa - como principal força política do grupo - a imposição de tais medidas e, para muitos gregos, é identificada como a responsável pela grande dívida assumida pelo país e pela consequente crise econômica que assola sua população.

Nesse sentido, a proposta da documenta 14 foi vista por muitos agentes do mundo da arte como uma tentativa de reparação, por meio da cultura, das medidas de austeridade impostas. Por outros, que consideraram a força da 
documenta enquanto importante instituição do cenário artístico contemporâneo, foi acusada de neocolonialismo, uma vez que literalmente ocupou instituições locais, incorporando nada ou muito pouco de suas questões e perspectivas particulares ao projeto. Houve também quem considerasse a ida à Atenas como um reforço das diferenças entre norte e sul global, e o voltar-se à cidade grega como uma busca por aprender como viver na/da crise.

Para além dessas questões e da indiscutível tensão imediata, a equipe curatorial afirmou que sua intenção foi extrapolar a dicotomia entre os dois países, compreendendo o título como um mote a partir do qual a mostra se desdobraria. Também ressaltaram a ideia de aneducation, ou seja, de que para o exercício da alteridade embutido no "learning from" se pressupunha abdicar de suas próprias verdades e certezas, em um processo de desaprendizagem. Contida nesta mesma ideia esteve um constante questionamento das narrativas oficias da História da Arte ocidental e de seus contextos e critérios de legitimação. Isso pode ser percebido por meio do discurso curatorial e de uma seleção de obras que desmontavam a perspectiva histórica eurocêntrica - não por a criticarem abertamente, mas por serem elas a própria alternativa a tal visão.

\section{ALEMANHA E GRÉCIA: ENFRENTAMENTOS HISTÓRICOS}

Imagens icônicas de Atenas, como as do Partenon, estiveram presentes em muitos momentos da documenta 14. Seja na monumental obra "Partenon de livros" (2017), da artista argentina Marta Minujin (fig.1), produzida em escala 1:1 no centro da Friedrichsplatz; nas pinturas acadêmicas realizadas por Cornelia Gurlitt no início do século XX; nos desenhos e estudos do projeto "The Erichthonean Museum of the Acropolis" (1991), do arquiteto grego Christos Papoulias; ou na evocação de J. J. Winckelmann, historiador e arqueólogo alemão, como o fundador da História da Arte enquanto disciplina em meados do século XVIII. Seu livro "História da Arte Antiga" (1764), bem como a primeira edição da revista "Atheneum" (1998-1800), fundada pelos irmãos August e Friedrich Schlegel e considerada uma das principais revistas do romantismo alemão, estão expostos em destaque na Neue Galerie e informam o público sobre como a arte grega foi elevada ao status de berço da arte ocidental e suas principais características, como harmonia, simetria e atenção às proporções foram compreendidas como o ideal de beleza durante séculos.

A documenta também enfatizou vínculos históricos existentes entre ambos países na 2a Guerra Mundial. O trabalho "Os desastres da guerra / Cavalo de Troia" (2017), do artista espanhol Daniel García Andújar, utilizou fotografias de dirigentes do alto escalão nazista em frente ao Partenon e a outros sítios arqueológicos gregos como símbolo da ocupação e submissão da cidade. 
A figura de Hitler também se fez presente na mostra na instalação com elevada carga irônica realizada em colaboração entre Piotr Uklanski e o duo McDermott \& McGough (fig. 2), no qual retratos do líder do III Reich estão expostos frente a frente com uma série de imagens retiradas do filme Olympia (1938), de Leni Riefenstahl. Ali a exaltação do ideal clássico grego com suas proporções perfeitas fica evidenciado como uma obsessão de Hitler, justificando sua

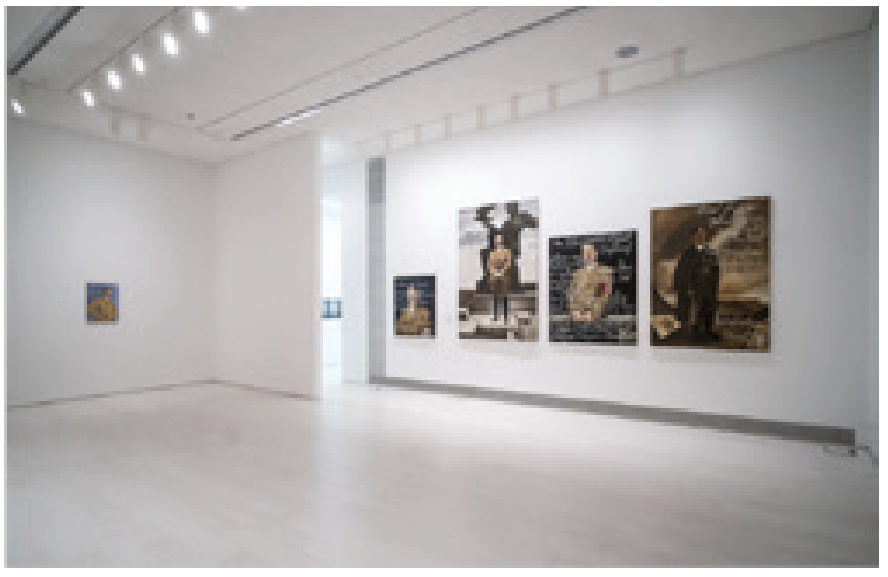
predileção por uma produção artística e arquitetônica de caráter neoclássico em detrimento da arte das vanguardas da época. A história da documenta com suas origens em um movimento de reconstrução da cidade de Kassel após a $2^{\text {a }}$ Guerra Mundial, tendo como objetivo a reinserção da Alemanha nas discussões relevantes da arte contemporânea internacional, está direta ou indiretamente presente na mostra e em suas publicações.

Figura 2. Piotr Uklanski e McDermott \& McGough, $O$ jeito grego (2017). Vista da instalação, EMST - National Museum of Contemporary Art, Atenas. Foto: Mathias Völzke.

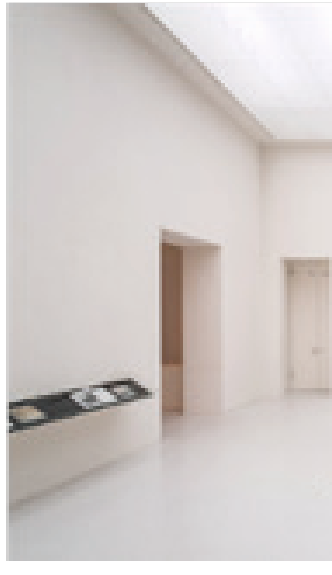

Figura 3. Maria Eichhorn, Livros de propriedade judaica adquiridos ilicitamente, (2016-17). Vista da instalação, Neue Galerie, Kassel. Foto: Mathias Völzke.
O caso Gurlitt é um exemplo de como dívidas históricas remanescentes do período da guerra foram centrais na construção do pensamento curatorial. Em fevereiro de 2012 foram descobertas mais de 1.400 obras de arte no apartamento do colecionador alemão Cornelius Gurlitt, na cidade de Munique. Algumas dessas obras já foram comprovadas como tendo pertencido a judeus que tiveram seus bens expropriados na $2^{\text {a }}$ Guerra Mundial. 0 pai de Cornelius foi um dos poucos marchands autorizados pelas autoridades nazistas a comer-

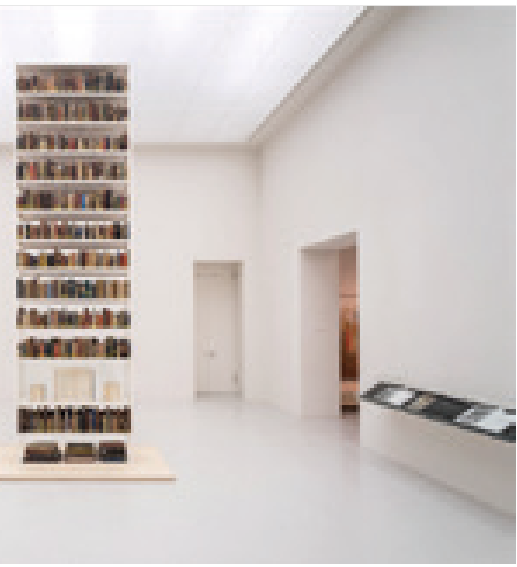
cializar a chamada arte degenerada. Tal notícia trouxe à tona a rememoração das violências e abusos da guerra e gerou reivindicações por parte de herdeiros pela reapropriação e repatriação desses bens. Tomando o caso Gurlitt como referência, Maria Eichhorn (fig. 3) apresentou uma grande estante repleta de livros confiscados ou roubados de famílias judias e respectiva pesquisa documental que comprovava sua propriedade.

A repatriação compreendida de forma mais ampla, aliás, foi uma constante na documenta 14. Isso pode ser percebido na relação estabelecida 
com a Grécia, que vem tentando reaver há décadas objetos, esculturas, relevos e colunas de museus como o Louvre em Paris, o British Museum em Londres, o Pergamon Museum em Berlim e o Metropolitan em Nova Iorque; mas também em seu caráter mais contemporâneo, ao atentar para os fluxos migratórios e de refugiados que chegam na Europa em grande quantidade, fugindo da guerra na Síria e de outras condições de perseguição e violência. Tema que é abordado na obra do paquistanês-britânico Rasheed Araeen (fig. 4), "Shamiyaana-Food for Thought: Thought for Change" (2016-17), na qual o artista construiu um restaurante na praça Kotzia, no centro de Atenas. 0 restaurante pretendeu ser um ponto de encontro para as diferenças, acolhendo refugiados, desempregados, moradores da região e visitantes da documenta. Ao redor de mesas comunitárias foram servidas refeições de receitas mediterrâneas preparadas utilizando apenas ingredientes locais. A intenção do artista em compartilhar alimento e histórias pessoais foi a de criar processos de empatia e integração entre pessoas que talvez não se conhecessem sob outras circunstâncias.

\section{OS STATEMENTS CURATORIAIS}

Ao propor uma miríade de debates de teor político, o evento gerou expectativas que provocaram reações bastante díspares a respeito do projeto expositivo. Se um conjunto de publicações, debates, encontros e workshops, bem como programas de rádio e televisão, compuseram sua programação pública e projeto educativo, muitas obras ficaram obliteradas pelo contundente discurso curatorial, que sobrepôs sua agenda - mesmo que necessária e urgente - à dos artistas.

Nesse sentido, a documenta 14 enquanto mostra de arte sofreu os reveses de escolhas feitas pela equipe curatorial. Apesar de tocar em temas caros ao mundo contemporâneo, teve dificuldades em captar a atenção do público e provocar o despertar de sensibilidades. Caracterizando-se como uma mostra predominantemente discursiva, prescindiu do elemento visual em diversos momentos, fazendo uso abundante de documentação, testemunhos, registros e arquivos variados. No extremo oposto, apresentou obras que meramente ilustravam conceitos dos statements curatoriais.
Figura 4. Rasheed Araeen, Shamiyaana - Food for Thought: Thought for Change (Alimento para o pensamento: pensamento para a mudança) (2016-17). Tendas com patchwork geométrico, cozinhar e comer, Kotzia Square, Atenas Foto: Yiannis Hadjiaslanis. 
2. A documenta, ou museu dos 100 dias, como também é chamada, possui tal duração como referência à mostra de arte degenerada realizada por Hitler, que se estendeu por igual período.

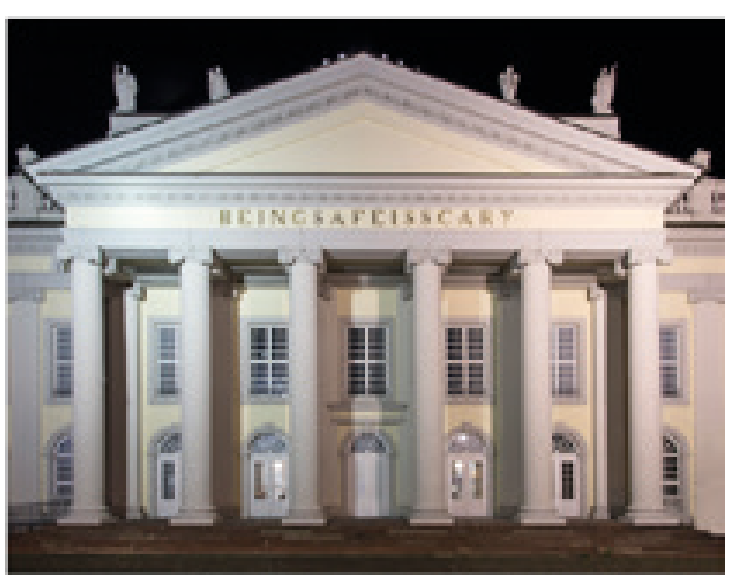

Figura 5. Banu Cennetoğlu, BEINGSAFE I S S CARY (ESTARSEGUROÉASSUSTADOR) (2017). Materiais variados, Friedrichsplatz, Kassel. Foto: Roman März.
Se a mostra não apresentou inovações significativas em termos de linguagens artísticas, tampouco apostou no impacto da experiência visual em seus visitantes. A documenta 14 convocou o espectador a uma constante reflexão a respeito de sua própria atuação no mundo, situando-o como agente histórico. Tal operação, no entanto, demanda tempo, disponibilidade, conscientização e envolvimento por parte do público, objetivo dificilmente atingido em mostras de grande escala.

Sem problematizar sua própria dimensão, o evento ao menos tratou de questionar suas políticas de exibição. Partindo da tradicional duração dos 100 dias $^{2}$ em cada cidade, a edição totalizou 163 dias e expôs obras de mais de 160 artistas. Esta foi a edição com maior número de artistas asiáticos, africanos e do leste europeu, além de ter apresentado um grande contingente de artistas pouco conhecidos no circuito internacional (objetivando desviar da pressão do mercado).

Toda a negociação institucional e com as autoridades alemãs e gregas também se mostrou de grande complexidade e com forte conotação política. Talvez o exemplo mais significativo disso tenha sido a "troca" do espaço do EMST - National Museum of Contemporary Art, em Atenas, pelo do Friedricianum, em Kassel. Na prática isso significou que, para a documenta poder usar o espaço do museu grego como uma de suas principais locações expositivas - questão fundamental para a realização da mostra em Atenas -, a instituição teve que abrir mão do mais tradicional espaço expositivo em Kassel para abrigar a coleção do EMST — predominantemente arte contemporânea grega - a partir de uma curadoria proposta pela direção do museu.

Ao impor sua vontade à documenta e ocupar o Friedricianum, a instituição grega rompeu, mesmo que discreta e temporariamente, com as tradicionais estruturas hierárquicas do sistema da arte. E, mesmo sem haver previsto tamanha barganha no projeto original, a equipe curatorial aceitou tal inversão de valores: ocupou e foi ocupada por Atenas, fazendo-se política tanto em sua temática, quanto em sua operação.

\section{O QUE A ARTE TEM PARA ENSINAR?}

Se partir de uma instituição canônica para questionar a criação e perpetuação de cânones históricos pode ser considerada uma das maiores contradições 
da documenta 14, abraçar tais contradições e conviver com elas talvez tenha sido seu ato mais corajoso.

Dos acertos e erros da curadoria, incitar e enfrentar discussões complexas e difíceis de serem travadas, muitas ainda sem respostas de qualquer natureza - seja estética e/ou ideológica - , foi um dos seus maiores méritos. Adam Szymczyk e sua equipe não recaíram no fetiche vanguardista ainda vigente de responder à constante aclamação por renovação das linguagens. Lidaram com questões amargas que, se não fosse a escala do projeto e seu constante apelo à intelectualização do que foi exposto, poderiam ter sido melhor fruídas em seu potencial e sensibilidade poéticos.

O questionamento de versões do passado para construir a possibilidade de revisões históricas mais inclusivas e menos universalizantes, fez emergir dissensos que não foram rapidamente apagados pelo percurso expositivo. A documenta 14 mostrou, assim, que são muitas as histórias recalcadas a serem expurgadas e reafirmou o papel fundamental da arte em um tempo que, como dizia a obra da artista turca Banu Cennetoğlu (fig. 5), "estar seguro é assustador."
3. A frase "estar seguro é assustador" foi retirada pela artista em 6 de abril de 2017 de um grafite existente na parede na Universidade Técnica Nacional de Atenas e exposta na fachada do Friedricianum em Kassel, substituindo as letras do nome do museu. 


\section{FICHA TÉCNICA}

Learning from Athens (Aprendendo desde/com Atenas)

Diretor artístico: Adam Szymczyk

\section{Atenas}

08 de abril a 16 de julho de 2017

47 localidades

\section{Kassel}

10 de junho a 17 de setembro de 2017

35 localidades

\section{REFERÊNCIAS}

LATIMER, Quinn; SZYMCZYK, Adam (editors). Documenta 14:

Daybook. Athens, 8 April - Kassel, 17 September 2017.

PRESTEL: Munich, London, New York, 2017, p.708.

Learning from Athens. An issue about documenta 14. Mousse

Contemporary Art Magazine. Issue \# 58. April-May 2017.

LATIMER, Quinn; SZYMCZYK, Adam (editors). The documenta 14

Reader. PRESTEL: Munich, Londodn, New York, 2017.

Site oficial da documenta 14, disponível em: <http://www.

documenta14.de/en/>, acesso em 11 de out de 2017.

\section{Bruna Fetter}

Pesquisadora e curadora independente, com doutorado em História, Teoria e Crítica de Arte pelo PPAGV/ UFRGS, Bruna Fetter visitou a documenta 14 nas cidades de Atenas e Kassel a convite do Goethe Institut.

(*) Texto enviado em novembro de 2017. 